\title{
A atuação do assistente social na residência multiprofissional em saúde da família: um relato de experiência
}

\author{
The work of the social assistant in the multiprofessional residence in family health: A report \\ of experiencia
}

\author{
Carolina Camilo da Silva Gois* \\ Alaíde Maria Morita Fernandes da Silva**
}

\section{Resumo}

Este artigo tem como objetivo apresentar a experiência do exercício profissional de um assistente social inserido na Residência Multiprofissional em Saúde da Família, a partir de uma reflexão sobre as dimensões constitutivas de seu trabalho, especialmente a técnico-operativa. O relato prioriza as ações desenvolvidas durante o curso, focalizando aquelas de caráter individual, coletivo, administrativo-organizacional, formação e capacitação. Tendo como perspectiva de análise a interprofissionalidade e a integralidade das ações em saúde, foi possível verificar que o cuidado em saúde também é responsabilidade do assistente social e sua atuação junto à equipe de profissionais se faz necessária para o enfrentamento das expressões da questão social que interferem no processo saúde-doença dos usuários.

Palavras-chave: Exercício profissional; Serviço Social; Atenção Básica; Residência Multiprofissional em saúde; Interprofissionalidade.

\begin{abstract}
This article aims to reflect the experience of the professional practice of a social worker inserted in the Multiprofessional Residency in Family Health. The report presents the work developed by the social worker during the residency, focusing on individual, collective, administrative-organizational actions and formation and capacity-building actions. This reflection of the work, having as perspective the interprofessionality and the integrality of the actions in health, made it possible to verify that health care is also the responsibility of the social worker and its performance with the team of professionals is necessary to face the expressions of the social question which interfere in the health-disease process of users.
\end{abstract}

Keywords: Experience Report; Social Service; Basic Attention; Multiprofessional Residence.

\footnotetext{
* Mestranda do Programa de Pós Graduação em Serviço Social e Política Social da Universidade Estadual de Londrina - UEL. Concluiu a Residência Multiprofissional em Saúde da Família - RMSF, 2016-2018, Departamento de Saúde Coletiva - UEL.

** Doutora em Serviço Social PUC/SP. Professora Adjunta do Departamento da Universidade Estadual de Londrina. Tutora de Núcleo do Serviço Social na Residência Multiprofissional em Saúde da Família - UEL.
} 


\section{Introdução}

A área da saúde constituiu-se como um dos principais campos de atuação do assistente social desde os primórdios da profissão. Naquela época, os serviços de saúde eram restritos para os trabalhadores que possuíam carteira assinada ou então, dependiam das Santas Casas de Misericórdia. O foco da saúde estava na doença, e não na sua promoção. Inserindo-se principalmente no campo hospitalar, a atuação do assistente social tinha um caráter complementar ao trabalho médico no que diz respeito a uma prática chamada curativista.

Com a nova Constituição de 1988 e a regulamentação da política de saúde pela Lei no 8.080/1990 iniciou-se um processo de descentralização dos serviços pautados nos princípios e diretrizes da universalidade, equidade, integralidade, hierarquização e participação social. As reivindicações do movimento de Reforma Sanitária culminaram na criação de um Sistema Único de Saúde - SUS e a saúde passou a ser um direito de todos e dever do Estado, sendo considerada a partir de um conceito ampliado ${ }^{1}$. Além disso, os serviços de saúde passaram a ser organizados de acordo com os níveis de atenção, classificados como básica, média e alta complexidade.

A saúde passa a ser compreendida como uma expressão da organização social e econômica do país tendo "como determinantes e condicionantes, entre outros, a alimentação, a moradia, o saneamento básico, o meio ambiente, o trabalho, a renda, a educação, a atividade física, o transporte, o lazer e o acesso aos bens e serviços essenciais (BRASIL, 2013)". Nessa nova forma de conceber a saúde "o trabalho em saúde passou a ser reconhecido como um campo de intervenção multiprofissional e, isto, transformou o cuidado em um objeto de diferentes profissões" (SILVA, 2013, p.3), como o assistente social, educador físico, psicólogo, nutricionista, entre outras profissões que ainda não tem o campo da saúde como um espaço consolidado como a profissão médica e de enfermagem.

Com essa perspectiva, foram criadas as residências multiprofissionais em saúde e em área profissional da saúde que, embora existentes desde 1975 no país, tiveram sua regulamentação em 2005, om a Lei no 11.129. São orientadas pelos princípios e diretrizes do

\footnotetext{
${ }^{1}$ A definição da Organização Mundial de Saúde - OMS - de 1948, em que a saúde passa a ser um estado completo de bem-estar físico, mental e social expressa uma ampliação do conceito de saúde sendo compreendida não apenas como ausência de doenças.
} 
SUS, como a universalidade e a integralidade das ações, a partir das necessidades e realidades locais e regionais.

No município de Londrina, a partir de uma parceria entre a Secretaria Municipal de Saúde e a Universidade Estadual de Londrina - UEL, criou-se a Residência Multiprofissional em Saúde da Família no ano de 2007 com o objetivo de formar profissionais para atuar no SUS e em especial na Estratégia Saúde da Família - ESF's. O curso está fundamentado em uma aprendizagem baseada na prática profissional, na educação de adultos, ou seja, na aprendizagem significativa e na integralidade do cuidado favorecendo práticas interdisciplinares e multiprofissionais na Atenção Básica.

Este relato se refere à atuação profissional em uma Unidade Básica de Saúde - UBS de uma residente de Serviço Social ao lado de outros residentes da fisioterapia, enfermagem, odontologia, farmácia, psicologia, nutrição e educação física durante dois anos. Os residentes compõem uma equipe do Núcleo de Apoio à Saúde da Família - NASF² do município, denominado de NASF-R. O território desta unidade abrange três bairros próximos, sendo que um deles em situação de maior vulnerabilidade social ${ }^{3}$, visto que foi fruto de uma ocupação e muitas famílias ainda não possuem regularização da Companhia de Habitação - COHAB do município. Trata-se, portanto, de um contexto de prática complexo que exige intervenções profissionais de diferentes áreas que propiciem o atendimento de necessidades de saúde e a melhoria da qualidade de vida dessa população.

Vasconcelos (2016) defende a importância do relato de experiência, pois ele pode potencializar a formação do sujeito da atividade profissional e proporcionar o debate de questões relevantes para o serviço social brasileiro. Para isso, é necessário não somente a exposição do cotidiano por escrito, mas também uma análise teórica crítica da experiência.

O relato de experiência está em consonância com a dimensão investigativa do assistente social sendo a sistematização da prática um elemento constitutivo do seu trabalho. Segundo Almeida (2007, p.8), a sistematização, "constitui uma dimensão importante do trabalho profissional que favorece uma reflexão contínua de suas respostas sócio-institucionais em suas relações de determinação com a dinâmica do ser social".

Compartilhamos do entendimento da autora de que além de permitir uma reflexão o relato de experiência proporciona a visibilidade das ações profissionais, o que pode

\footnotetext{
${ }^{2}$ A partir da Portaria no 2436, de 21 de setembro de 2017, a equipe do Núcleo de Apoio à Saúde da Família NASF passa a ser denominada de Núcleo Ampliado de Saúde da Família e Atenção Básica (NASF AB).
} 
contribuir para o reconhecimento do trabalho do assistente social junto aos outros profissionais no âmbito da atenção básica. Essa é uma questão que diz respeito ao trabalho deste profissional e, portanto, uma reflexão sobre a sua prática se justifica, na medida em que há uma insuficiência de produção acadêmica nessa temática.

Para a realização do relato de experiência foi utilizado como instrumento o diário de campo, com anotações no período de dezembro de 2016 a agosto de 2017, o qual foi dedicado a coleta de dados, bem como a observação do cotidiano profissional. Cabe destacar que a observação aqui está sendo utilizada menos como instrumento de coleta de dados nas diversas modalidades previstas na literatura, porém, mais devido ao fato de integrar o contexto da observação.

No diário de campo foram registradas as ações profissionais desenvolvidas contribuindo assim para a finalidade da pesquisa. De acordo com Triviños (1987),

[...] as anotações realizadas no diário de campo, sejam elas referentes à pesquisa ou a processos de intervenção, podem ser entendidas como todo o processo de coleta e análise de informações, isto é, compreenderiam descrições de fenômenos sociais, explicações levantadas sobre os mesmos e a compreensão da totalidade da situação em estudo ou em um atendimento (apud, LIMA, MIOTO, DAL PRÁ, 2007, p. 100).

As anotações no diário de campo foram realizadas semanalmente ou conforme a identificação da necessidade do registro, focalizadas nos seguintes aspectos: situação vivenciada; origem da demanda e a atuação do profissional. Esses aspectos para registro e análise foram escolhidos para evidenciar quais as principais demandas de atuação do profissional e de identificar se a equipe multiprofissional reconhece o assistente social como um sujeito no cuidado em saúde.

Nesse sentido, o diário de campo foi um importante instrumento de coleta de dados para o registro das observações dos atendimentos realizados, das impressões obtidas do contexto social dos usuários, das percepções do ambiente de trabalho e da dinâmica da equipe, e a partir daí, foi realizada a análise da realidade social com o apoio teórico escolhido.

Assim, este artigo está organizado da seguinte forma: a primeira parte aborda a atuação do assistente social na atenção básica de acordo com as legislações brasileiras e com a literatura científica; em seguida exploramos o a dimensão técnica-operativa do serviço social a partir do processo de inserção do assistente social na Residência 
Multiprofissional em Saúde da Família; a partir disso, apontamos os desafios identificados durante a residência para o trabalho multiprofissional, e por fim, são apresentadas as considerações finais diante do relato de experiência.

\section{A Atenção Básica como campo de atuação do assistente social}

A Política Nacional de Atenção Básica - PNAB (2017) tem como objetivo produzir a atenção integral da pessoa a partir do desenvolvimento de ações de promoção, prevenção, reabilitação, vigilância em saúde, entre outras, por meio de uma equipe multiprofissional. Ainda de acordo com a PNAB, a atenção básica tem como principal estratégia para sua consolidação a Estratégia Saúde da Família - ESF. As equipes de Saúde da Família são formadas por um conjunto mínimo de profissionais, sendo estes o médico, enfermeiro, auxiliar de enfermagem e o agente comunitário de saúde - ACS. Essa equipe atende uma população adstrita em seu território, sendo responsável pelo cuidado integral desses usuários.

No ano de 2008, o governo federal criou o Núcleo de Apoio à Saúde da FamíliaNASF, tendo como diretrizes a integralidade, interdisciplinaridade e intersetorialidade, humanização e promoção da saúde. O NASF é composto por profissionais de diferentes áreas que se propõe a desenvolver um trabalho interprofissional para apoiar as equipes de ESF no cuidado da saúde dos usuários. Pode ter em sua composição o assistente social, porém no município de Londrina, o profissional de serviço social ainda não compõe as dez equipes de NASF.

Algumas ações a serem desenvolvidas para o apoio especializado são os atendimentos compartilhados, que consistem numa intervenção interprofissional com atividades específicas de cada núcleo profissional; bem como ações coletivas em seu território de abrangência. Utiliza-se para isso ferramentas tecnológicas, como o apoio matricial3, clínica ampliada, projeto terapêutico singular e projeto de saúde no território (BRASIL, 2009).

Nas Diretrizes do NASF (2009) há também a descrição das atividades previstas a

\footnotetext{
3 “O Apoio Matricial em saúde objetiva assegurar retaguarda especializada a equipes e profissionais encarregados da atenção a problemas de saúde". Porém o realiza de maneira personalizada e interativa. Opera com o conceito de núcleo e de campo. Assim, um especialista com determinado núcleo apoia especialistas com outro núcleo de formação, objetivando a ampliação da eficácia de sua atuação (CUNHA; CAMPOS, 2011, p. 964).
} 
serem desenvolvidas pelo assistente social nessa equipe, que deve ser de acordo com a realidade de cada território. Dentre elas estão: atendimento individual, familiar e grupal; criação de grupos educativos e de convivência; articulação e parceria com a rede intersetorial, elaboração de estudo social; participação em eventos de aperfeiçoamento $e$ produção de conhecimentos; planejamento e gestão. Além disso, são esperadas ações em conjunto com as equipes de saúde e com os demais profissionais do NASF, tendo como objetivo efetivar o direito à saúde e a ampliação da cidadania.

Assim, a atenção básica é um campo de atuação de diversos profissionais e para a preparação desses trabalhadores para atuar nesse campo há que se ressaltar a importância das Residências Multiprofissionais em Saúde. De acordo com o mapeamento realizado pela Associação Brasileira de Ensino e Pesquisa em Serviço Social -ABEPSS, o Serviço Social está inserido prioritariamente nos programas de modalidade multiprofissional, criados em 2009. Já, em relação ao campo de atuação do assistente social, foi identificado que grande parte dos programas de residência é desenvolvida em espaços hospitalares, sendo uma pequena parte com atuação na atenção básica. Por outro lado, ainda que realizada em hospitais, a pesquisa apontou que há uma articulação com os demais níveis de atenção (2013, p.156).

Além desses profissionais do programa de residência, a Secretaria de Saúde do Município conta com quatro assistentes sociais que ficam no nível central cujo trabalho se organiza por regiões, atendendo as UBS's quando necessário. Porém, esse importante apoio e, apesar de ser uma referência para nosso trabalho, não se constitui como a principal atividade desempenhada por esses assistentes sociais não possibilitando, portanto, um acompanhamento contínuo de nossa atuação nessas unidades de saúde.

\section{A experiência como assistente social na Residência Multiprofissional em Saúde da Família}

A inserção na residência foi um processo permeado por incertezas e dificuldades para compreender o papel do assistente social junto à equipe de residentes e dos trabalhadores daquela unidade, especialmente a equipe de ESF composta por enfermeiros, médicos e técnicos de enfermagem. Essas dificuldades expressam, por um lado, uma cultura pautada no modelo médico-hegemônico consolidada ao longo da história do campo da saúde em que, outros profissionais além da equipe mínima têm o desafio de identificar e construir o seu espaço de atuação num contexto sócio institucional que nem sempre 
favorável à esta proposta de reorganização do trabalho.

Nesse sentido, estudos ressaltam que o trabalho do assistente social em uma unidade de saúde é permeado por inquietações associadas, como afirma Costa (2006, p.36): “À imprecisão da profissão (o que é, o que faz), cujos traços voluntaristas e empiristas, no entender de muitos (as) assistentes sociais contribuem para fragilização e consequente desqualificação técnica do Serviço Social."

É nesse contexto de trabalho que o assistente social se insere e que exige compreender que o trabalho em saúde se caracteriza pela produção do cuidado que, segundo Merhy (1998), é trabalho vivo, fruto do encontro entre o trabalhador e usuário, com a finalidade de atender às suas necessidades de saúde. Esse cuidado faz parte de todo processo de trabalho e depende da dimensão cuidadora, que é constitutiva de toda profissão da área da saúde. Sendo assim, o cuidado em saúde também é de responsabilidade do assistente social, pois o mesmo é um trabalhador da área da saúde.

Por ser uma aprendizagem em serviço, ao inserir-se na equipe de profissionais de saúde de uma UBS, o assistente social e outros núcleos profissionais deverão contribuir para a produção do cuidado. Isso significa que, segundo Merhy (2004), na produção de um ato de saúde coexistem vários núcleos, como o núcleo específico, que consiste nos saberes peculiares de cada profissional, mas também o núcleo cuidador, que atuam os processos relacionais do campo das tecnologias leves, ${ }^{4}$ pertencente a todos os trabalhadores.

Buscando superar essas inquietações, problematizamos as ações realizadas na UBS tendo como referência a Lei 8.662/1993, que dispõe sobre a profissão de assistente social, pelo Código de Ética, pela Lei 8.080/1990, sendo a lei orgânica da saúde, pelos Parâmetros de Atuação do Assistente Social na Saúde, pelas resoluções e cadernos do Ministério da Saúde sobre a atenção básica e NASF-que discorre sobre o processo de trabalho do serviço social junto à equipe multiprofissional e pelo referencial de saúde coletiva apreendido durante a realização da Residência Multiprofissional em Saúde da Família.

Ao mesmo tempo, cabe ressaltar que as diretrizes curriculares para o curso de Serviço Social evidenciam que a formação profissional implica na capacitação teórico

\footnotetext{
${ }^{4}$ As tecnologias leves fazem parte do complexo processo de trabalho em saúde, que conforme Merhy (2004, p.110) aponta é o conjunto de " momentos de falas, escutas e interpretações, no qual há a produção de uma acolhida ou não das intenções que estas pessoas colocam neste encontro; momentos de cumplicidades, nos quais há a produção de uma responsabilização em torno do problema que vai ser enfrentado; momentos de confiabilidade e esperança, nos quais se produzem relações de vínculo e aceitação."
} 
metodológica, ético-política e técnico-operativa do profissional. Ou seja, o exercício profissional do assistente social é constituído por uma totalidade, formada pelas três dimensões: ético-política, teórico-metodológica e técnico-operativa (SANTOS; SOUZA FILHO; BACKX, 2017, p. 27). Esta última, diz respeito aos instrumentos e técnicas que materializam as ações profissionais, e segundo as autoras, essas três dimensões possuem particularidades:

\footnotetext{
Particularidades essas que permitem que a dimensão técnico-operativa se constitua na "forma de aparecer" da profissão, na dimensão "pela qual a profissão é conhecida e reconhecida". Ela é o "modo de ser" da profissão, o modo como aparece no movimento das três dimensões (SANTOS; FILHO; BACK, 2017).
}

Nessa perspectiva, nosso entendimento para o trabalho do assistente social na residência não se reduz à sua dimensão técnica operativa, que diz respeito aos instrumentos e técnicas, mas que, além disso, as ações também possuem uma dimensão ético-política e teórica-metodológica que direcionam a atuação do profissional.

Nesse relato, focamos na dimensão técnico-operativa que exemplifica as ações e dá visibilidade ao trabalho desenvolvido, mas isso sem excluir as demais dimensões, pois, as mesmas estão intrinsecamente articuladas. A partir dessa perspectiva, reconhecemos a importância do instrumental técnico na reflexão e avaliação do trabalho do assistente social na atenção básica e na equipe de profissionais de uma UBS, conforme apresentamos a seguir.

\section{A dimensão técnico-operativa do trabalho do assistente social residente}

No início da residência foi elaborado um plano de atuação em conjunto com a Tutora de Núcleo do Serviço Social na residência que foi se modificando de acordo com as experiências vivenciadas, seguindo a dinamicidade da realidade. Buscando explicitar com maior precisão as ações do assistente social no plano, buscamos agrupa-las, conforme propõe Trindade (2013), considerando que essa forma de classificar as ações do assistente social se aproxima da realidade profissional, ou seja: ações de caráter individual; ações de caráter coletivo; administrativo organizacional e ações de formação profissional, capacitação e pesquisa.

De acordo com o plano de atuação elaborado, bem como o diário de campo, foi possível identificar ações conforme sua natureza, assim como o seu objetivo, os 
procedimentos e instrumentos para efetivá-la.

A demanda por atendimento individual para o assistente social na UBS era proveniente da equipe e/ou de forma espontânea pelos usuários ao saberem da existência deste profissional naquela unidade.

Esses atendimentos, que também podiam ser compartilhados com outros profissionais, além de propiciar o contato direto e, se possível, estabelecer um vínculo com o usuário, exigiam a investigação de sua realidade social e familiar para a identificação de suas necessidades e sua situação de saúde. Na busca de atender as necessidades identificadas e as estratégias de ação, o momento propiciava, também, a orientação aos usuários quanto aos serviços, programas, projetos e benefícios sociais.

As ações de caráter individual tiveram como principal objetivo contribuir no processo saúde-doença do usuário e de sua família e viabilizar o acesso às políticas e direitos sociais. Para a identificação das necessidades sociais foram realizados atendimentos individuais e utilizados a entrevista e a visita domiciliar como instrumentos. Dentre essas ações estão as atividades de natureza emergencial assistencial, que como afirma Costa (2006) demandam a mobilização e articulação de recursos assistenciais para o acesso a transporte, medicamentos, órtese, prótese, alimentos, roupas, abrigo, traslado, atestados/declarações. Nesses atendimentos individuais então era realizado a identificação das necessidades sociais e na maior parte essas eram relacionadas a essas necessidades de caráter emergencial

Como o trabalho do assistente social não envolvia a administração de benefícios, como acontece nos Centros de Referência de Assistência Social - CRAS, nem alguns recursos para suprir essas demandas emergências, as respostas as necessidades esbarravam-se nesse limite. O procedimento nessas situações era o encaminhamento ao CRAS, com contato telefônico anterior para o técnico do serviço para esclarecimento da situação do usuário, mas em alguns momentos, devido à grande demanda atendida pelo CRAS e a escassez dos recursos, foi necessária a articulação com entidades assistenciais religiosas que atendem a comunidade local.

Considerando que o atendimento às necessidades materiais da população de baixa renda exige parcerias entre o poder público e a sociedade civil, essas entidades auxiliam nessa questão fornecendo, conforme seus critérios, por exemplo, cestas básicas, medicamento e roupas. Dentre as demandas/necessidades apresentadas pelos usuários na 
UBS, era recorrente a procura por leites especiais para bebês e, quando eles não estavam dentro dos critérios do programa de leite do município, era inevitável o pedido de doações em instituições filantrópicas e/ou supermercados do território para assegurar o direito de alimentação da criança.

Esse problema da falta de recursos e a necessidade de recorrer a instituições não governamentais para atender as demandas da população são historicamente constitutivas das políticas sociais no Brasil e expressam a desigualdade econômica e social resultante do modo de produção capitalista interferindo no trabalho do assistente social. Além disso, aponta os limites e fragilidades da política de saúde e as demais políticas sociais que, no momento atual, não são tidas como prioridades para o governo.

Em relação às ações de caráter coletivo nas UBSs, há uma demanda de desenvolvimento de trabalho com grupos específicos como o grupo de educação em saúde com os adolescentes do território, e neste mesmo sentido, também as ações educativas nas escolas do bairro. Há, também, uma expectativa por parte dos demais profissionais quanto ao preparo do assistente social para a organização e mobilização da comunidade para a participação nos mecanismos de controle social, como o Conselho Local e Municipal de Saúde.

As ações de caráter coletivo tinham por objetivo abranger vários usuários e eram realizadas na maioria das vezes, em conjunto com outros profissionais da equipe, uma vez que o programa de residência tem como finalidade o agir multiprofissional. Essas ações tiveram como objetivo comum à socialização de informações e a criação de espaços para a discussão de temas de interesse dos usuários e de prevenção à saúde. Os instrumentos empregados nessas ações coletivas foram: oficinas com o grupo de adolescentes, palestras para o público jovem nas escolas, discussões em salas de espera e participação em ações de educação em saúde específicas da área de odontologia, nutrição e educação física. Para isso, foram utilizados recursos audiovisuais, dinâmicas de grupo e materiais educativos. Essas atividades exigiram um planejamento em conjunto da equipe de residentes, assim como a articulação com escolas e/ou outros espaços para a prática coletiva.

O atendimento coletivo também é considerado como uma ação de caráter coletivo, pois envolve mais de um usuário. Dentre àqueles que foram realizados durante a experiência, destacamos um atendimento familiar com sete irmãos de um usuário. Este havia sido diagnosticado com câncer e estava acamado, debilitado e necessitando de 
cuidados, tanto para o auxílio nas atividades da vida diária, quanto na questão financeira. Até aquele momento somente uma irmã estava cuidando do usuário e sentiu-se sobrecarregada com os muitos cuidados exigidos pelo tratamento, procurando assim o serviço social da UBS. Então, foi convocado todos os irmãos, que eram os únicos familiares do usuário, para um atendimento, sendo comunicado a necessidade do cuidado com o irmão e como cada um poderia contribuir.

A partir dessa atuação, foi observado no acompanhamento da situação uma maior responsabilização de todos com a situação de saúde do usuário o que facilitou os encaminhamentos feitos pela equipe de enfermagem e no atendimento médico que puderam contar com mais familiares para, por exemplo levá-lo ao especialista e ao hospital.

Para além desses atendimentos, outra ação coletiva importante para o serviço social é a criação e assessoramento dos conselhos de saúde. Na UBS em questão, o conselho local de saúde havia sido desativado a algum tempo. Quando a equipe de residentes entrou, foi realizada algumas estratégias para a retomada do conselho, como: conversa com a coordenação da UBS, contato com os "antigos" líderes do território, sensibilização dos funcionários acerca da importância dos conselhos.

Porém, foi observado que essas pessoas que poderiam contribuir com a retomada do conselho, ainda não haviam entendido a necessidade de um conselho local, além disso, a UBS que os residentes estavam teve que mudar de espaço e alocar-se com outro posto de saúde, devido uma reforma que durou onze meses, o que gerou várias dificuldades no processo de trabalho de todos, dificultando assim, a retomada do conselho local de saúde.

Outra ação que demandou a articulação da equipe de profissionais de saúde foi o desenvolvimento do Grupo de Adolescentes, chamado de Projeto Joaquim. Esse grupo se deu com os adolescentes do Serviço de Convivência e Fortalecimento de Vínculos do CRAS do território. As intervenções eram uma vez ao mês, no período de um ano, e teve como objetivo a realização de atividades de educação em saúde. Desde o seu planejamento e execução acontecia de forma interdisciplinar o que tornou as atividades ainda mais produtivas.

Apesar de, nessa intervenção, o assistente social, ter sido o profissional que mobilizou os outros trabalhadores a desenvolver essa atividade com os adolescentes, foi imprescindível a contribuição de todos os envolvidos, uma vez que, as diversas categorias possuem saberes e responsabilidades distintas que são fundamentais para a realização dos 
serviços em saúde. Embora em determinados momentos alguns dos profissionais se sobressaiam em relação aos outros, a saúde do usuário não pode se restringir à prática de apenas uma categoria ou profissional. (GOMES; PINHEIRO; GUIZARDI, 2005, p.108)

As ações desenvolvidas com os adolescentes fazem parte das ações socioeducativas do assistente social, previsto no Parâmetro de Atuação dos Assistentes Sociais na Saúde como um eixo central de atuação. Além desses parâmetros, Costa (2006) traz a educação, informação e comunicação em saúde como um eixo prioritário da inserção do assistente social na saúde.

No processo de trabalho dos profissionais na unidade também estão incluídas as ações de caráter administrativo-organizacional na unidade. Para o assistente social é um momento de organização e planejamento das atividades a serem desenvolvidas para o atendimento tanto das demandas dos usuários, equipe e coordenação.

Dentre as atividades destacamos a articulação com a rede socioassistencial e de saúde que se desdobra na participação nas reuniões e estudo de casos dessa mesma rede. Para que essas ações fossem registradas, outras atividades eram primordiais, como a digitação no E-SUS $A B^{5}$ - e anotação no prontuário além da elaboração de relatório social quando solicitado por algum órgão e a produção do diário de campo, utilizado neste artigo.

Já as ações de caráter administrativo-organizacional estão relacionadas aos procedimentos de atendimento às demandas institucionais tais como: registro das informações geradas pelos atendimentos; preenchimento de fichas e prontuários. Além desses procedimentos que atendem às necessidades do serviço, no que se refere aos usuários, verificou-se o desenvolvimento de inúmeras ações relacionadas à articulação com a rede de serviços e encaminhamentos para essa rede, tendo como objetivo a viabilização do acesso a outras políticas sociais, assim como o fortalecimento do trabalho em rede.

As ações de formação e capacitação estiveram sempre presentes na medida em que a residência é uma modalidade de ensino em serviço e por isso tivemos a participação

\footnotetext{
${ }^{5}$ O Ministério da Saúde diz que" A estratégia E-SUS AB busca reestruturar e integrar as informações da Atenção Básica em nível nacional. O objetivo é reduzir a carga de trabalho na coleta, inserção, gestão e uso da informação na $A B$, permitindo que a coleta de dados estejam inserida nas atividades já desenvolvidas pelos profissionais. Por meio do e-SUS AB, a rede de serviço que compõe a Atenção Básica alimentará o Sistema de Informação". Então cada profissional de saúde na atenção básica, possui acesso ao e-sus e deve alimentá-lo". Disponível em:<http://dab.saude.gov.br/portaldab/o que e esus ab.php>. Acesso em: 20 nov. 2017.

As residências multiprofissionais são compostas por docentes e profissionais que estão inseridos nos campos de atuação. O tutor de núcleo, de acordo com as resoluções do Ministério da Saúde, deve ser um docente da mesma área de formação do residente que possui a função de orientação acadêmica a fim de realizar discussões teóricas, teórico-práticas e da prática do residente.
} 
nos módulos teóricos, em eventos científicos e/ou da rede de serviços; mas além dessas atividades externas a UBS, também havia participação nas reuniões da própria unidade de saúde e a realização do apoio matricial para toda equipe de saúde. Essas atividades têm como objetivo aprofundar o conhecimento teórico sobre a área que se atua e a reflexão da prática, sendo necessário o desenvolvimento do espírito investigativo para a pesquisa e melhor fundamentação da prática.

É preciso ressaltar que as ações elencadas se inserem no contexto de uma Residência Multiprofissional cujo objetivo é o desenvolvimento de habilidades e capacidades profissionais para o trabalho em equipe, o apoio matricial, ações de caráter coletivo (sala de espera, grupo com adolescentes) e atendimentos compartilhados.

A partir das anotações feitas no diário de campo, classificamos as origens das demandas $^{6}$ que chegam até o serviço social por meio da procura espontânea e pelos encaminhamentos realizados pela equipe. A primeira foi identificada como a principal origem das demandas, isto é, quando um usuário chega até a UBS e solicita o atendimento com o assistente social. Essa informação sugere que o profissional de serviço social, na unidade de saúde onde o estudo foi realizado é conhecido pela comunidade, assim como o seu trabalho, ou seja, ele está sendo reconhecido pelos usuários do território onde atua. Esse conhecimento da população sobre a atuação do assistente social nesse território se deve também pelo tempo que a residência multiprofissional faz parte da equipe da unidade.

Em relação aos encaminhamentos, foi possível diferenciar aqueles realizados internamente pela equipe de trabalhadores, que configura a dinâmica do trabalho na unidade de saúde, daqueles encaminhamentos externos, que se efetivam pela articulação com a rede de atenção à saúde ${ }^{7}$ e serviços sócios assistenciais, como o CRAS, escolas, hospitais e outros oriundos das reuniões de sub-rede. ${ }^{8}$

\footnotetext{
${ }^{6}$ Tratamos aqui o conceito de demanda a partir Cecílio (2001) que a define como a tradução das necessidades mais complexas dos usuários, em que essas são modeladas pela oferta que os serviços fazem.

7“As redes de atenção à saúde são organizações poliárquicas de conjuntos de serviços de saúde, vinculados entre si por uma missão única, por objetivos comuns e por uma ação cooperativa e interdependente, que permitem ofertar uma atenção contínua e integral a determinada população, coordenada pela atenção primária à saúde - prestada no tempo certo, no lugar certo, com o custo certo, com a qualidade certa e de forma humanizada -, e com responsabilidades sanitárias e econômicas por esta população" (MENDES, 2010, p.2300).

${ }^{8}$ No município de Londrina foi instituída a: rede de atenção à criança e adolescente que se materializa por meio das reuniões de rede e sub-rede. Nas reuniões de rede participam representantes da política de educação, assistência social e saúde, já nas reuniões de sub-rede, participam representantes locais dessas políticas, como os profissionais do CRAS, escolas municipais e estaduais e da UBS. Esta reunião tem como objetivo o trabalho intersetorial e a discussão dos casos apresentados. Disponível em:
} 
Os encaminhamentos internos se configuram em maior quantidade, o que pode indicar que o assistente social está sendo acolhido pelos demais trabalhadores como um profissional que pode contribuir para o cuidado em saúde. A sua inserção na equipe multiprofissional amplia a visibilidade das múltiplas determinações da situação de saúde da população as quais exigem um maior aprofundamento do conhecimento da realidade social. Como afirmam Mioto e Nogueira (2009, p. 223), “o Serviço Social na saúde está sendo reconhecido tanto no plano legal como através da legitimação social das suas ações profissionais".

As ações de caráter individual são bastante conhecidas e utilizadas pelos assistentes sociais, porém se faz necessário maior aproximação com as práticas coletivas, que segundo Trindade (2013) há uma baixa incidência dessa modalidade de intervenção, que se deve até mesmo pela dificuldade no uso dos instrumentos e técnicas para essa prática pelos profissionais. Assim, ações como educação em saúde, realizadas durante a residência, permitiram que o profissional vá além das ações de caráter emergencial e das práticas para suprir a demanda das necessidades objetivas da população.

Por fim, o assistente social também identifica demandas possíveis de sua atuação através da observação do fluxo da unidade, ou até mesmo quando é solicitado por um profissional para uma ação pontual. Esse processo possibilita identificar outros aspectos da realidade do usuário não identificados por outros profissionais ou até por ele mesmo, mas que precisam ser acolhidas. Isto é, a demanda imediata do usuário pode não ser a sua demanda real, pois "apesar de ser a problemática inicial que o mobilizou, nem sempre é a sua demanda real; na maioria das vezes ela é o veículo (ou o meio mediador) que porta a capacidade de conduzir o assistente social à busca da demanda real, da essência" (GUERRA, 2009, p.81).

\section{Desafios do trabalho em equipe multiprofissional}

O trabalho em equipe multiprofissional perpassou a atuação do assistente social residente durante todo o curso, pois este consiste num eixo teórico-metodológico da residência.

<http://www.londrina.pr.gov.br/dados/images/stories/Storage/sec_assistencia/pdf/Fluxolnteresetorial/Perg untas\%20e\%20Respostas.pdf> Acesso em: 20. nov 2017. 
Peduzzi $(1998,2001)$, o trabalho em equipe multiprofissional é uma modalidade de trabalho coletivo que é construído por meio da relação recíproca, de dupla mão, entre as múltiplas intervenções técnicas e a interação dos profissionais de diferentes áreas, configurando, através da comunicação, a articulação das ações e a cooperação (apud PEDUZZI, 2009, p. 275).

Nesse sentido, o trabalho em equipe exige a interação e comunicação entre os diferentes saberes e contribui para o cumprimento do princípio da integralidade das ações. Além disso, o SUS vem exigindo cada vez mais que os profissionais de saúde atuem de maneira interdisciplinar. A Política Nacional de Atenção Básica de 2012 traz como uma das atribuições de todos os profissionais da área a realização do trabalho interdisciplinar e em equipe.

Os profissionais que ingressam na residência são em maioria recém-formados e, por isso, estão na busca pelos conhecimentos necessários à atuação. $O$ assistente social também compartilha dessa falta de experiência prática e, além disso, como já mencionado anteriormente, a atenção básica conta com poucos profissionais atuando. Foi necessário empenhar-se por novos conhecimentos necessários ao processo de trabalho, mas que não foram acessados durante a graduação. Por isso, foi importante ir até o CRAS do território para conhecer os benefícios e serviços que são oferecidos, bem como os critérios, também ao INSS, pois já era visível a buscar dos usuários por informações a respeito da previdência e assim fornecer orientações assertivas acerca dos direitos dos usuários.

Além das ações profissionais desenvolvidas apenas pelo assistente social, o trabalho em equipe multiprofissional envolveu um conjunto de estratégias, como: atendimentos compartilhados com outros profissionais, desenvolvimento de grupos, realização de sala de espera e atividades de educação em saúde.

Os atendimentos compartilhados se deram pelas múltiplas necessidades apresentadas pelos usuários, sendo por iniciativa do assistente social ou de outro profissional. Essa modalidade de atendimento acontecia preservando a ética profissional sem excluir a especificidade de cada saber, uma vez que,

A interdisciplinaridade não representa a anulação da disciplinaridade, nem a especificidade de cada saber, mas a possibilidade de uma compreensão integral do ser humano e do processo saúde-doença, objeto do trabalho em saúde, passa necessariamente por uma abordagem interdisciplinar e por uma prática multiprofissional (ARAÚJO; ROCHA, 2007, p. 461).

Em muitos momentos foi indispensável a atuação do assistente social e da 
nutricionista, em casos de usuários com anemia grave, em que a família não possuía condições econômicas de prover a sua alimentação, ou com o fisioterapeuta, em situações como, por exemplo, que exigiam informações sobre direitos previdenciários. Esse processo possibilitava o aprofundamento do conhecimento da realidade do usuário e os encaminhamentos necessários.

Ressaltamos também o trabalho do assistente social com o psicólogo, especialmente em situações de violência (doméstica e/ou sexual), e em situações em que os usuários eram diagnosticados com transtorno mental. Esses atendimentos exigiam além do saber específico do assistente social, o conhecimento da psicologia que, juntos, se complementavam e possibilitavam maior resolutividade das ações.

Algumas visitas domiciliares também requeriam mais de uma especialidade devido à complexidade do caso. Em uma situação, uma usuária procurou o serviço social para obter informações sobre a realização de documentos de identificação para seu irmão, que até pouco tempo estava em situação de rua. Ela trouxe o irmão para morar com ela devido à um problema grave de saúde e a partir do que ela contava foi verificada a necessidade de uma visita domiciliar com a enfermagem, nutrição e o médico.

Nesse caso, o usuário estava em um quadro de febre alta e como já realizava tratamento pelo hospital do câncer a enfermeira o encaminhou com urgência para essa instituição. Além disso, a nutricionista da unidade iniciou o acompanhamento devido o usuário estar desnutrido e o médico passou a assistir o caso. O serviço social foi necessário para além das orientações que deram início ao atendimento, devido à conflitos familiares que envolviam a questão do cuidado com o irmão.

Além dos atendimentos compartilhados foi possível a realização de salas de espera pela equipe NASF-R que abordou temas relevantes para a saúde dos usuários, tais como: alimentação saudável, violência contra mulher, direitos sociais e saúde do homem. Esses temas foram trabalhados em conjunto como por exemplo a sala de espera para prevenção de quedas em idosos desenvolvida pelo assistente social e em parceria com o educador físico.

Essa dinâmica de trabalho acontecia também com a equipe de saúde da família, por meio da comunicação e troca de saberes entre os membros. Essa comunicação dava-se principalmente nas reuniões semanais com os trabalhadores da ESF e o NASF residência, cujos membros traziam a situação de um usuário em acompanhamento e solicitavam a 
intervenção dos profissionais especializados decidindo, assim, as ações a serem executadas em conjunto.

No decorrer da residência o apoio matricial, estratégia que possibilita a socialização de conhecimento de cada núcleo profissional e uma ferramenta tecnológica utilizada pelos NASF's, teve também a participação do assistente social residente. Foi observada a necessidade de o serviço social realizar um matriciamento para os demais profissionais e equipe de ESF sobre a ética no cuidado em saúde. Esse matriciamento trouxe uma reflexão com os trabalhadores da unidade sobre o seu processo de trabalho, conduzindo-os a pensar se o modo como eles estavam atendendo e/ou realizando as visitas domiciliares estavam de acordo com a ética profissional, preservando a privacidade e o sigilo das informações obtidas.

Outra ação que demandou a articulação da equipe de profissionais de saúde foi o desenvolvimento do Grupo de Adolescentes, chamado de Projeto Joaquim. Esse grupo se deu com os adolescentes do Serviço de Convivência e Fortalecimento de Vínculos do CRAS do território. As intervenções eram uma vez ao mês, no período de um ano, e teve como objetivo a realização de atividades de educação em saúde. Desde o seu planejamento e execução acontecia de forma interdisciplinar o que tornou as atividades ainda mais produtivas.

Apesar de, nessa intervenção, o assistente social, ter sido o profissional que mobilizou os outros trabalhadores a desenvolver essa atividade com os adolescentes, foi imprescindível a contribuição de todos os envolvidos, uma vez que, as diversas categorias possuem saberes e responsabilidades distintas que são fundamentais para a realização dos serviços em saúde. Embora em determinados momentos alguns dos profissionais se sobressaiam em relação aos outros, a saúde do usuário não pode se restringir à prática de apenas uma categoria ou profissional. (GOMES; PINHEIRO; GUIZARDI, 2005, p.108)

As ações desenvolvidas com os adolescentes fazem parte das ações socioeducativas do assistente social, previsto no Parâmetro de Atuação dos Assistentes Sociais na Saúde como um eixo central de atuação. Além desses parâmetros, Costa (2006) traz a educação, informação e comunicação em saúde como um eixo prioritário da inserção do assistente social na saúde.

Além da articulação com a equipe de ESF e com o NASF residência, o assistente social, no seu processo de trabalho, buscou a articulação com os trabalhadores de outros 
serviços de saúde, como de hospitais e CAPS- Centro de Atendimento Psicossocial, além de profissionais do CRAS, CREAS- Centro Especializado de Assistência Social, serviços de convivência e outros. De acordo com Costa,

[...] pode-se afirmar que o assistente social se insere, no interior do processo de trabalho em saúde, como agente de interação ou como um elo orgânico entre os diversos níveis do SUS e entre este e as demais políticas sociais setoriais, o que nos leva a concluir que o seu principal produto parece ser assegurar - pêlos caminhos os mais tortuosos - a integralidade das ações (COSTA, 2006, p. 39).

Como afirmam Ciampone e Peduzzi (2000, p. 144) “há que se considerarem duas dimensões inerentes ao trabalho em equipe: a articulação das ações e a interação dos profissionais". Por outro lado, é preciso destacar que nem sempre essa interação ocorre, pois muitas vezes os trabalhadores em saúde entendem o trabalho em equipe como 0 agrupamento de profissionais em um mesmo espaço. E isso dificulta a articulação das ações.

Outro elemento dificultador do trabalho em equipe observado é a permanência de espaços de comunicação entre os trabalhadores, como as reuniões de equipe, conforme mencionamos. Essas reuniões permitem a discussão das ações e a troca de saberes, porém tendo em vista o momento atual de sucateamento das políticas sociais e do setor público, a gestão cobra dos profissionais o atendimento à demanda imediata. Diante desse contexto, a manutenção desses espaços de discussões é constantemente atacada exigindo que os profissionais busquem reafirmar a sua importância.

O trabalho em equipe interprofissional é uma prática indispensável para o alcance da integralidade no atendimento ao usuário e a falta de comunicação entre os trabalhadores pode gerar dificuldades no cumprimento desse princípio, uma vez que,

\footnotetext{
A fragmentação existente entre os profissionais e suas respectivas práticas nos serviços de saúde constitui, então, obstáculo significativo ao princípio da integralidade. Em virtude disso, a análise do "trabalhar em saúde" e a superação dessa fragmentação emergem como aspectos importantes para o debate em direção à materialização desse princípio constitucional (GOMES; PINHEIRO; GUIZARDI, 2005, p. 107).
}

Ou seja, apesar dos desafios, o assistente social e os demais profissionais da área da saúde têm como atribuição desenvolver um trabalho em equipe para além do agrupamento dos profissionais para que haja a comunicação, troca de saberes e articulação das ações e, assim, os usuários serão os principais beneficiados. 


\section{Considerações finais}

A realização do curso de Residência Multiprofissional em Saúde da Família proporcionou o contato com diferentes profissionais e o acesso a referenciais teóricos não vistos anteriormente durante a graduação em Serviço Social, contribuindo de forma significativa na formação para o trabalho em saúde. Dentre os desafios dessa modalidade de ensino em serviço está o desenvolvimento de habilidades para o trabalho em equipe na medida em que é necessário escutar o que o outro profissional traz de contribuição e, ao mesmo tempo, ajustar os saberes e práticas em benefício dos usuários.

A interprofissionalidade exige uma postura profissional de abertura para que ocorra uma integração dos saberes e a criação de um projeto comum, a fim de que as ações sejam mais resolutivas e abrangentes. Percebeu-se que, as ações desenvolvidas com os outros profissionais se constituem em um processo contínuo de aprendizagem em que um saber complementa o outro na perspectiva do conceito ampliado de saúde.

Com a experiência vivenciada foi possível perceber que o assistente social, em uma equipe multiprofissional, pode contribuir para sensibilizar o olhar dos outros profissionais para as necessidades sociais que interferem no processo saúde-doença dos usuários, uma vez que, a formação da maioria dos trabalhadores de saúde tem como foco os aspectos biológicos da situação que se apresenta para a equipe nos serviços.

Este relato se propôs a trazer elementos para uma reflexão sobre a potência do trabalho em equipe, das ações desenvolvidas pelo assistente social e os demais profissionais mostrando que o cuidado é responsabilidade de todos os trabalhadores da saúde. Acreditase que há necessidade de se aprofundar no debate sobre o assistente social na atenção básica, mas espera-se que este trabalho possa contribuir para a prática profissional de outros assistentes sociais tendo em vista que a insuficiente produção científica na área.

\section{Referências}

ALMEIDA, N. L. T. Retomando a temática da "sistematização da prática" em Serviço Social. p.8. In: MOTA, A. E. et al. (Orgs.). Serviço Social e saúde: formação e trabalho profissional. São Paulo: Cortez, 2006.

ARAUJO, M. B. S.; ROCHA, P. M. Trabalho em equipe: um desafio para a consolidação da estratégia de saúde da família. Ciênc. saúde coletiva, Rio de Janeiro: v.12, n.2, 2007, p.455464. Disponível em: http://www.scielo.br/scielo.php?script=sci_arttext\&pid=S1413$81232007000200022 \&$ Ing=en\&nrm=iso. Acesso em: 20 nov. 2017. 
BATISTELLA, C. Abordagens contemporâneas do conceito de saúde. In: FONSECA, A. F.; CORBO, A. M. A. (Org.). O território e o processo saúde-doença. Rio de Janeiro: EPSJV/Fiocruz, 2007.

BRASIL. Constituição (1988). Constituição da República Federativa do Brasil. Brasília, DF. 1988. Disponível em: http://www.planalto.gov.br/ccivil 03/constituicao/constituicao.htm. Acesso em: 20 nov. 2017.

BRASIL, Ministério da Saúde. Caderno de Atenção Básica, n.27, 2009. Diretrizes do NASFNúcleo de Apoio a Saúde da Família, Brasília, 2009. Disponível em:

http://bvsms.saude.gov.br/bvs/publicacoes/caderno atencao basica diretrizes nasf.pdf. Acesso em: 15 nov. 2017.

BRASIL, Ministério da Saúde. Caderno de Atenção Básica, n.39, 2014. Ferramentas para a gestão e para o trabalho cotidiano, Brasília, v. 1, p.116. 2014. Disponível em:

http://bvsms.saude.gov.br/bvs/publicacoes/nucleo apoio saude familia cab39.pdf. Acesso em: 10 nov. 2017.

BRAVO, M. I. S.; MATOS, M. C. Projeto Ético-Político do Serviço Social e sua relação com a Reforma Sanitária: elementos para o debate. In: MOTA, A. E. et al. (Orgs.). Serviço Social e saúde: formação e trabalho profissional. São Paulo: Cortez, 2006. p.1-22.

CASTRO, M.M.DE.C.E.C. O serviço social nos programas de residência em saúde: resultados iniciais do mapeamento da ABEPSS. Temporalis. Brasília: $n$. 26, jul/dez. 2013. Disponível em: http://periodicos.ufes.br/temporalis/article/view/5309/4944. Acesso em: 30 jul. 2018.

CECILIO, L. C. O.; PINHEIRO, R.; MATTOS, R. A. As necessidades de saúde como conceito estruturante na luta pela integralidade e equidade na atenção em saúde. Os sentidos da integralidade na atenção e no cuidado à saúde, v. 1, 2001. p. 113-126.

CIAMPONE, M. H. T.; PEDUZZI, M. Trabalho em equipe e trabalho em grupo no programa de saúde da família. Rev. bras. enferm., Brasília, v. 53, n. spe, p. 143-147, Dec. 2000. Disponível em: http://www.scielo.br/pdf/reben/v53nspe/v53nspea24.pdf. Acesso em: 20 nov. 2017.

COSTA, M. D. H. O trabalho nos serviços de saúde e a inserção dos assistentes sociais. In: MOTA, A. E. et al. (Orgs.). Serviço Social e saúde: formação e trabalho profissional. São Paulo: Cortez, 2006. Disponível em: http://www.fnepas.org.br/pdf/servico social saude/texto27.pdf. Acesso em: 20 abr.2018.

CONGRESSO BRASILEIRO DE ASSISTENTES SOCIAIS, 15., 2016 , Olinda. Anais [...]. Olinda, 2016.

CUNHA, G. T.; DE SOUSA CAMPOS, G. W. Apoio matricial e atenção primária em saúde. Saúde e Sociedade, v. 20, n. 4, p. 961-970, 2011.

GOMES, R.S; GUIZARD, F.L; PINHEIRO, R. A orquestração do trabalho em saúde: um trabalho sobre a orquestração das equipes. In: PINHEIRO, R; MATTO, R. A (org.). Construção social da demanda: direito à saúde, trabalho em equipe, participação e espaços públicos. Rio de Janeiro: Cepesc/Uerj, 2005. p.105-111. 
LIMA, T. S.; MIOTO, R. C. T.; DAL PRÁ, K. R. A documentação no cotidiano da intervenção dos assistentes sociais: algumas considerações acerca do diário de campo. Revista Textos \& Contextos. Porto Alegre, v. 6, n. 1, ja./jun. 2007. Disponível em:

http://revistaseletronicas.pucrs.br/ojs/index. php/fass/article/viewFile/1048/3234. Acesso em: 08 nov. 2017.

MERHY, E.E.; FEUERWERKER, L.C.M. Novo olhar sobre as tecnologias de saúde: uma necessidade contemporânea. In: MANDARINO, A.C.S.; GOMBERG, E. (Orgs.). Leituras de novas tecnologias e saúde. São Cristóvão: Editora UFS, 2009. p.29-74.

MERHY, E. E. O ato de cuidar: a alma dos serviços de saúde. In: BRASIL. Ministério da Saúde. Secretaria de Gestão do Trabalho e Educação na Saúde. Departamento de Gestão da Educação na Saúde. Ver-SUS Brasil: caderno de textos. Brasília: Ministério da Saúde, 2004. p.108-137.

MENDES, E. V. As redes de atenção à saúde. Ciência \& Saúde Coletiva, v. 15, n. 5, 2010.

MIOTO, R. C. T.; NOGUEIRA, V. M. R. Serviço Social e Saúde - desafios intelectuais e operativos. Ser Social, Brasília, v. 11, n. 24, jul/dez, 2009. Disponível em:

http://periodicos.unb.br/index. php/SER Social/article/view/374. Acesso em: 20 nov. 2017.

SANTOS, C.M.; FILHO, R.S.; BACKX, S. A dimensão técnico-operativa do Serviço Social: questões para reflexão. In: SANTOS, C.M.; BLACKX, S.; GUERRA, I. A dimensão técnicooperativa no Serviço Social: desafios contemporâneos. São Paulo: Cortez, 2017.

SILVA, A. M. M. F. da. Produção do cuidado em saúde e o Serviço Social. São Paulo, 2013. p.120. Tese (Doutorado em Serviço Social). Pontifícia Universidade Católica de São Paulo. 2013.

SOMMERMAN, A. A emergência da pluri, da inter e da transdisciplinaridade do século XX. In: . Inter ou transdisciplinaridade?. São Paulo: Paulus, 2006. p.28-31.

PEDUZZI, M.; CIAMPONE, M. H. T. Trabalho em equipe. Pereira IB, Lima JCF, organizadores. Dicionário da educação profissional em saúde. 2a ed. Rio de Janeiro: Fundação Oswaldo Cruz, 2009.

TRINDADE, R. L. P. Ações profissionais, procedimentos e instrumentos no trabalho dos assistentes sociais nas políticas sociais. In:SANTOS, Claudia Mônica; BACK, Sheila; GUERRA, Yolanda (Org). A dimensão técnica operativa no serviço social. 2 ed. Juiz de Fora: UFJF, 2013. p.76-108. 